\title{
Informe sobre la Organización de las horas libres y de recreo.
}

Las horas libres de que disponen los estudiantes peruanos en los tres grados de enseñanza, primaria, secundaria y superior son en número muy variado, debiclo al medio regional en que reciben la enseñanza, a la calidad de las poblaciones que habitan y a las diferencias de planes de estudios, los quese encuentran, en plenas reforma. Sin embargo se pucde calculanam promedio de horas libres de los estudiantes en las siguientes cifras: 28 horas semanales a los alumnos de enseñanza primaria, incluyendo los domingos y los días de fiestas religiosas y civiles; de 29 horas para los alumnos de enseñanza media bajando hasta 20 en los últimos años; de 24 a 30 horas en la enseñanza superior de las universidades y escuelas especiales. En estos tres grados no se han tomado en cuenta, como es natural, las horas destinadas a la alimentación y a los cuidados personales. Hay un Io \% de estudiantes de primaria y secundaria y al rededor de un $25 \%$ en la enseñanza superior que trabajan. Estos se ocupan por horas o por todo el día y no disponen en consecuencia sino de muy pocas horas y esto ocasionalmente.

En general, la manera como emplean los estudiantes 
prinarios este tiempo es en el juego libre, los deportes ejecutados sin control alguno, los ejercicios en los gimnasios públicos y en los juegos propios de la niñez, tales como: trompos, bolas, cometas, y algunos juegos de apuesta. Las diversiones clásicas de los niños van cediendo el campo por la imitación de los deportes, las colecciones, el cinema y las lecturas de libros de emoción. Muchas revistas circulan entre los escolares de indole más sensacionalista que educativa. Hay algunos clubs infantiles que van desapareciendo a consecuencia de la infiltración de actividades imitativas de la política, designadas con el nombre de células infantiles, lo que ocasiona su represión y clausura.

En los alumnos de enseñanza secundaria se dedica una parte pequeña a las actividades infantiles y el resto a las que son propias del adolescente. Los deportes; el cinema, los paseos, la lectura de revistas y novelas de dudosa procedencia, constituyen las principales ocupaciones. Un número apreciable se dedica a las prácticas religiosas y culturales. No reciben educación sexual y no se han organizado aún las sociedades juveniles que dirijan las actividades extra escolares de este periodo tan significativo en la formación de la personalidad del adolescente. Unas pocas sociedades de boyscouts y de girls-guides, ejercitan a los jóvenes en actividades de servicio social, pero la mayor parte carece de complementos culturales de esta suerte.

Los jóvenes universitarios, en estos últimos tiempos son más asiduos asistentes a las bibliotecas, a las conferencias y a los actos de regocijo espiritual. Han dado de mano a las actividades politicas dentro del claustro y sus ocios los distribuyen entre el deporte más como espectáculo que como ejercicio, el cinema, las diversiones sociales, los espectáculos públicos y la discusión sobre los temas de palpitante actualidad. Se puede decir que en su vida intelectual y volitiva predomina la opinión sobre el análisis, el sentidọ de la 
afirmación aún sin el auxilio de la experiencia. A pesar de los esfuerzos de la Universidad de San Marcos en proporcionar una apreciable biblioteca, un gimnasio y una revista en la Facultad de Letras, que refleja el nuevo espíritu universitario, manifestado en la publicación de los trabajos de los catedráticos y alumnos, hace falta centros culturales anexos que deben establecerse y que son los siguientes:

I. - Un club de bellas artes en el que se den audiciones musicales, se promuevan certámenes de dibujos y pinturas de los alumnos y se ejerciten en la declamación y en el canto coral.

2. - Una organización atlética y de deportes, anexada al departamento de educación física y formada por líderes universitarios que permita inducir, si es posible, a todos los alumnos a la práctica de los ejercicios físicos al aire libre, obligatoriamente.

$3 .^{\circ}$ - La constitución de un comité de personas amantes de la cultura nacionalista que aporte los medios materiales y las direccionestécnicas, en las-excursiones que metódicamente debengrealizarilos lialumnosscon el fin de conocer el territorio nacional para apreciar los lugares históricos y los problemas económicos, sanitarios, sociales y geográficos cuya solución depende de su preparación profesional.

4. - - La instalación de una estación de radio, como ya lo ha principiado a organizar la Facultad de Letras de esta Universidad, para emitir y recibir la voz universitaria y que pueda servir a la veż para que catedráticos y alumnos realicen la extensión cultural en el pueblo.

5. - Promover conferencias y demostraciones sobre los productos nacionales, st1s formas de explotación, de manufactura, movimiento industrial y comercial con el objeto de despertar interés por las posibilidades económicas y dar al estudiante una idea práctica de lo que el país representa co- 
mo valor comercial. Las proyecciones luminosas y el cinema pueden completar estos medios de información.

6. - - La formación de un comité para organizar una modesta editorial universitaria con el auxilio del Estado, para que éste proporcione maquinarias y permita que los útiles de impresión sean libres de derechos de aduana. Así la Universidad llevaría la palabra escrita a todo el país, a un costo reducido y podría dar al libro el juego cultural que tanto interesa a la juventud.

Lima, Julio I 3 de 1936.

E. Ponce Rodríguez.

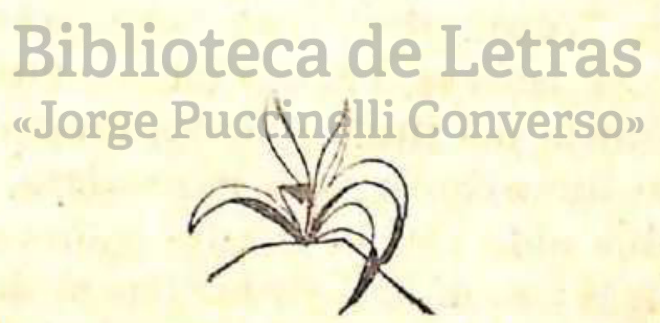

